\title{
The advantages of cognitive approach for enterprise management in modern conditions
}

\section{Robert A. Karayev}

E-mail: karayevr@rambler.ru

\section{Natella Yu. Sadikhova}

E-mail: natella5@rambler.ru

Institute of Control Systems, National Academy of Sciences of Azerbaijan

Address: 9, B. Vahabzade Street, Baku AZ 1141, Azerbaijan

\begin{abstract}
The paper provides a brief description of cognitive management, which opens up unique opportunities for the effective management of enterprises in modern complex and unstable conditions. The problems of commercializing this promising paradigm are discussed. It is pointed out that the main, critical one of these problems is due to the lack of developed engineering of cognitive management. A conceptual framework for solving this problem is proposed, based on the convergence of the ideas and methods of the "cognitive school" and the empirical experience gained in knowledge engineering. The results of using the conceptual framework in four research projects of different industry orientations, with different internal conditions and different dynamics of the external environment are presented. The engineering prospects of the proposed framework are discussed in terms of the commercialization of the cognitive school identified by H. Mintzberg, B. Ahlstrand and D. Lampel 30 years ago.
\end{abstract}

Key words: cognitive management; conceptual framework; analysis and choice technology; cognitive approach.

Citation: Karayev R.A., Sadikhova N.Yu. (2020) The advantages of cognitive approach for enterprise management in modern conditions. Business Informatics, vol. 14, no 2, pp. 36-47.

DOI: 10.17323/2587-814X.2020.2.36.47 


\section{Introduction}

$\mathrm{R}$ esearch into strategic management is usually said to have begun in the mid1960s. Sometimes 1951 is cited [1]. But studies on military strategic construction appeared much earlier: for instance, Sun Tzu's famous treatise on the art of war is attributed to the 5th century BC. The range of studies on strategic management began to expand rapidly in the early 1980s, when business leaders faced the growing complexity of the business world and realized the need for strategic analysis of the prospects for their business success.

In recent years, business has come up against new challenges that require a substantial revision of established concepts and traditional strategic management tools [2]. One of the most serious problems that managers have been facing recently is understanding complex causal chains that determine the impact of the external and internal conditions of an enterprise on the goals and properties of the strategy being developed. Today, this problem is compounded by the growing complexity and instability of the economic environment, leading to numerous uncertainties and risks.

In the new environment, the use of traditional strategic management tools encounters serious limitations everywhere, dictating the need to create new tools that are appropriate to the research nature of modern management practice [3]. Ideas and methods of the cognitive approach open up great opportunities for creating such tools $[4,5]$. Cognitive approach-based support tools can be regarded as tools of a new generation forming within the framework of the research paradigm of the cognitive science [6]. This paradigm today is focused on solving a wide range of complex problems of the modern world in a variety of fields: economics, sociology, politics, ecology, industry, business, emergency situations, etc., including strategic management.
There are many studies devoted to cognitive management. However, most of them have been conducted by management theorists, mathematicians or psychologists, and they are very far from the demands of management practice. More than thirty years have passed since the birth of the cognitive school of management [7]. Numerous publications widely discuss the tempting and promising prospects of this school, however, to date, there is still no developed cognitive management engineering, which (as in the case of all other knowledge-based technologies) is a critical link in cognitive analytics [8].

It is significant that of all the publications on cognitive management we have analyzed (academic journals, monographs, conference proceedings) we have not come across a single one written by a specialist with experience in the practical development of commercial models. Most of those publications analyze the problems of the cognitive process and discuss theoretical problems for future research.

At the same time, long-term practice convincingly indicates that an important prerequisite for creating the engineering of all knowledge-based technologies without exception [8] is critical analysis and generalization of the results of applied developments that form the empirical "axiomatics" of the problem area, which is no less important than numerous theoretical constructions.

Even thirty years ago, the authors of [7] pointed out that the body of work of cognitive school followers "forms not so much a tight school of thought as a loose collection of research, which seems, nonetheless, to be growing into such a school. If it can deliver on its intentions, it could very well transform the teaching and practice of strategy as we know it today" [7]. 
In our opinion, the solution to this complex "stagnant" problem can be facilitated by the creation of advanced cognitive management engineering, which includes two basic components: a single conceptual framework that combines the entire variety of existing strategic concepts and a systematic library of cognitive tools that allow these concepts to be implemented in concrete strategic projects.

Apparently, the possibly most effective way to solve this problem is a convergence of ideas and methods of the cognitive school of strategic management and the empirical experience gained in knowledge engineering [9]. In this paper, we propose one of the possible versions of the conceptual framework constructed in this way, presenting the results of the development and testing of cognitive models for four research projects differing in industry orientation, internal conditions and different dynamics of the macroeconomic environment obtained within this framework. The goal in these projects was not to create commercial support tools. The main goal pursued by the authors of the projects was to test the possibility of using a single conceptual framework when creating applied models for enterprises of various configurations. The developments were of a research nature and were carried out from 2004 to 2018 by four independent groups.

In the following paragraphs, we provide:

(1) a general description of the cognitive approach to the problem of strategic management modeling reflecting the characteristics of enterprise management in an unstable economic environment;

(2) the proposed conceptual framework of cognitive management, integrating modern cognitive experience in a single ontological project;

(3) a brief description of the cognitive models developed during the implementation of these projects;
(4) some most significant, in our opinion, results obtained by us in the development and testing of models, which, taking into account the specifics of concrete projects, can nevertheless be of interest to a wide range of specialists concerned with engineering issues.

The findings presented in the conclusion reflect not only the opinions of the model makers, but also the opinions of the project stakeholders, as well as the experience in developing cognitive models in other areas.

\section{General description of the cognitive approach}

Modern ideas of the cognitive approach to the management of complex problem situations have been described in numerous publications, e.g. $[4,5,10]$. Within the framework of these ideas, cognitive modeling is a cognitive map-based modeling aimed at studying a problem situation and finding the optimal (in one sense or another) strategy for managing this situation. The main components of cognitive models are the cognitive map and methods of its analysis.

\subsection{Cognitive map}

A cognitive map is an explicit representation of "mental models" [11] of management subjects about the conceptual structure, laws or patterns of a problem situation.

The main components of a cognitive map are:

(1) a set of basic factors characterizing the problem situation (the management object and its external environment);

(2) cause-and-effect (causal) relations between basic factors represented by certain formalisms.

Currently, the formalism of digraphs is used to build cognitive maps in most cases [12]. The vertices of the digraph are the factors of 
the problem situation, and the arcs are the causal relations between them.

On the set of basic factors, we set:

$\downarrow$ a subset of target factors reflecting the desired state of the management object,

$\uparrow$ subsets of uncontrollable and controllable factors of the management object,

a subset of external environment factors that may affect the problem situation.

For each of the factors, its current value or the tendency of its variation is established. For causal relations, the nature of the impact of the cause factors on the effect factors is established.

Situation management consists in such a change in the controllable factors of the management object that would lead to the desired changes in the target factors.

It should be noted that digraph-based maps are currently the most popular in cognitive research, however the range of formalisms that can be used in the building of cognitive maps is much wider. Along with the digraph formalism, cognitive maps can also employ such formalisms as M. Minsky's frames, genetic networks, relational matrices of the American Society for Quality, scenario networks, etc.

\subsection{Cognitive map analysis methods}

Cognitive map analysis methods are developed to conduct model experiments on a cognitive map in order to solve a wide range of management problems, e.g. choosing the strategic goals of an enterprise, strategic diagnostics of the external and internal environment of an enterprise, developing an "optimal" (in one sense or another) enterprise strategy in an uncertain and dynamic economic environment, auditing a strategy, assessing its stability and effectiveness, adjusting strategy in a changing environment, etc.

\section{Conceptual framework of cognitive management}

The problem of finding the best strategy in today's business environments is extremely complex. It can be fully regarded among the class of complex problems, the solution of which is beyond the competence of the traditional theory of strategic management.

The "phenomenon of complexity" is due to five major features of modern strategic management, which management practice faces everywhere nowadays. Such features are: the uniqueness of each strategic project, multifactoriality, multidimensionality (multidisciplinarity), dynamism and uncertainty of the problem of strategic choice, the substantial role of strategy developers' mentality, as well as strategic decision makers.

There have been known attempts to create one-size-fits-all cognitive support tools for strategic problem solvers [13-16]. However, practice shows that in the complex and diverse environment in which modern enterprises operate, the creation of universal tools is futile and does not justify itself. What is needed is not universal tools but some unified methodology that allows building cognitive models for concrete enterprises for a concrete period of time, taking into account the strategic vision of the owners and managers of this enterprise [17].

The first step in the formation of this kind of methodology is the development of a conceptual framework of cognitive management that is common to all its applications. The fundamental fact here is that a conceptual framework in such a complex problematic environment cannot be developed on the basis of traditional formal axiomatic approaches. The empirical approach widely used in knowledgebased technologies [18] is apparently more appropriate here.

Within this approach, the conceptual framework of cognitive management can be represented as follows: 


$$
P(C M):\left.S^{o}(C) \Rightarrow S^{c}(C)\right|_{U(P)}
$$

where $P(C M)$ is the full knowledge of the problem area of cognitive management;

$S^{\circ}(C)$ is the current state of the analyzed business situation set on the cognitive map;

$S^{c}(C)$ is the target state of the analyzed business situation set on the cognitive map;

$U(P)$ is the management strategy establishing the sequence of strategic steps that ensure the transition of the business situation from So to Sc.

It is clear that the full knowledge $P(C M)$ should reflect the accumulated theoretical and practical experience of the problem area.

The study and critical analysis of the vast material devoted to cognitive modeling of management problems [19-26], as well as the authors' personal experience suggest that the full knowledge $\mathrm{P}(\mathrm{CM})$ can be represented as an ontological project including the following sections:

1. Applied problems that can be solved with the help of cognitive management engineering. The problems can be presented in the form of separate questions to which answers can be obtained and, thus, they are the subject of engineering.

2. A set of postulates or axioms that show what assumptions were made during the development of engineering. The axioms or postulates describe the conditions and limits of applicability of engineering.

3. The list of concepts of strategic management that are currently in place in management science and practice.

4. A systematized library of applied tools to implement these concepts in specific strategic projects.

4.1 Support tools for choosing the concept of strategic enterprise management.
4.2. Support tools for choosing the language of presentation (formalism) of cognitive maps.

4.3. Support tools for structural and functional identification and parameterization of cognitive maps.

4.5. Many methods of analysis of cognitive maps for solving applied problems.

The structure of $\mathrm{P}(\mathrm{CM})$ presented is essentially a "protoframe" of engineering and solves two important problems.

First, it expands the traditional idea of schemes for solving applied problems of strategic management by including the stages of postulating cognitive analysis, choosing the concept of strategic management, choosing an appropriate language for representing cognitive maps, carrying out structural and functional identification and parameterization of cognitive maps. Without addressing these issues, cognitive business analysis in most cases loses all practical meaning.

Second, it systematizes the directions of efforts aimed at the development and accumulation of applied capabilities of cognitive analysis in solving issues that are important in the context of management practice, including but not limited to:

$\checkmark$ identification of contradictions between the goals set by the management subjects;

$\checkmark$ analysis of the effectiveness of the controllable factors of the cognitive map and their importance according to the degree of impact on the established goals;

$\downarrow$ designing various options for management strategies ("self-development strategy" and various versions of "controlled development strategies");

$\checkmark$ modeling the dynamics of alternative management strategies in various scenarios of the development of the external environment and choosing the optimal (in one sense or another) strategy; 
studying the stability of the selected strategy in critical situations caused by possible external environment threats;

$\downarrow$ monitoring the strategy in the process of its implementation;

$\checkmark$ retrospective analysis of the adequacy of the cognitive map and its adjustment.

The production part of the ontological project today includes a lot of publications related to solving the main problem of strategic management - choosing the enterprise development strategy.

A preliminary systematization of these studies can be done using descriptors characterizing their engineering efficiency:

1. the horizon of analysis, which the tool is focused on (short-term, medium-term, long-term);

2. the nature of the external environment of enterprises for which the tool is developed (static, dynamic);

3 . the stage of development of the strategy for which the tool is intended (strategic identification of the external and internal environment of the enterprise, conceptualization of the strategic vision of the owners and top management of the enterprise, formalization of the strategic vision in the form of a cognitive map, development (selection) of map analysis methods, testing of the cognitive model [27]);

4. the level of development of the tool (theoretical proposal, demonstration prototype, research prototype, functional prototype, industrial version [9]).

We use this systematization to characterize the cognitive models developed during the implementation of the four mentioned projects.

\section{Cognitive analysis projects}

Project 1. An assessment of the strategic prospects of an offshore oil company in the Caspian Sea region, the operating conditions of which are characterized by typical modern trends: fluctuations in world oil prices caused by geopolitical factors, the global financial crisis, growing government regulation, tightening environmental standards. The study was carried out jointly with the Petroleum Engineering Department of the Texas A\&M University (College Station, Texas, USA) under a creative cooperation agreement with BP Azerbaijan.

Project 2. Identification of key competencies for the strategic development of a telecommunications company - a regional dealer of Microsoft, Cisco Systems, HP, Intel. The company is engaged in the development, installation and maintenance of industrial, administrative and medical information systems, as well as IP and CTI telephony systems for telecom service providers and corporate clients.

Project 3. Analysis of management effectiveness at a poultry enterprise of a holding company in Baku. The problem was caused by the critical situation due to an increase in prices for raw materials and feeds, a decrease in prices for finished products, an increase in competitive pressure, difficulties in obtaining commercial loans, insufficient qualifications of managerial personnel, as well as a decrease in the share of profits allocated to the refinancing of the enterprise (in particular, due to the corruptive pressure of the regulatory authorities).

Project 4. Selection of regional ICT management strategy. The project was implemented with financial support from the Ministry of Communications and Information Technologies of Azerbaijan. Its relevance was due to the fact that the transition of the country to the information (digital) 
economy made the issue of the impact of information and communication technologies (ICT) on the economic growth of various economic entities vital. The issue was most acute at the regional level. This problem is quite complicated. Until now, it has been the subject of numerous discussions and has been known in economic practice for over thirty years as R. Solow's paradox ("the productivity paradox") [28].

The problem is multifactorial, uncertain and dynamic and cannot be solved using traditional econometric methods. Those interested in this issue can browse the Internet to see how many unsuccessful attempts to tackle it have been made in international practice. In particular, the authors of such attempts used such methods as correlation and regression analysis, estimation methods based on the Cobb-Douglas production function, research based on the methodology of economic impact analysis. Mention may be made of the iSociety project supported by Microsoft and PricewaterhouseCoopers that examined the impact of ICT on the efficiency of everyday business in the UK, as well as the McKinsey study that analyzed the channels of the impact of ICT on productivity based on the study of relevant business processes.

In our case, a cognitive approach was used to solve the problem posed [29]. The results of a large-scale Economist Intelligence Unit study (EIU, 2004), which is a combination of system analysis methodology and business review, were used as a conceptual basis at the stage of strategic concept selection.

Model experiments conducted during the implementation of this project have shown that cognitive modeling opens up fundamentally new opportunities not only for assessing the economic impact of ICT, but also for managing this impact, i.e. for carrying out an effective ICT management strategy.

\section{Brief description \\ of the developed \\ cognitive models}

The main characteristics of the models developed in the above projects were:

$\downarrow$ the adopted concept of strategic management;

$\downarrow$ the cognitive map formalism reflecting the logic of the adopted concept;

$\uparrow$ methods for building and analyzing a cognitive map;

$\downarrow$ scales for assessing the values of basic factors and causal relations of the map.

The characteristics of the models developed in these projects are shown in Table 1.

Examples of building cognitive maps can be found in $[29,30]$.

\section{Discussion}

The experience of developing and testing cognitive models in these projects has shown the following:

1. In practical business problems, cognitive modeling faces the same difficulties as other intelligent (knowledge-based) technologies. This is an issue of high-quality expert knowledge used in building cognitive models, all kinds of "traps" and "expert paradoxes" [9] that arise when working with experts, difficulties in choosing an appropriate detail level for cognitive maps, and an urgent need for an intermediary specialist (knowledge engineer, meta-interpreter cognitologist), etc.

2. Cognitive modeling acquires practical significance only within the framework of the strategic diagnostic methodology, which includes the stages of macroeconomic and marketing analysis in the context of the external environment dynamics. Ignoring these stages reduces cognitive models to mathematical objects that are far removed from the realities of business practice. 


\section{Characteristics of the cognitive models developed during} the implementation of the projects

\begin{tabular}{|c|c|c|c|c|}
\hline \begin{tabular}{c|} 
Project \\
No. (project \\
development \\
level)
\end{tabular} & $\begin{array}{l}\text { Adopted } \\
\text { concept } \\
\text { of business } \\
\text { strategy }\end{array}$ & $\begin{array}{l}\text { Structural } \\
\text { type } \\
\text { of CM }\end{array}$ & $\begin{array}{l}\text { CM building } \\
\text { and analysis } \\
\text { methods }\end{array}$ & $\begin{array}{c}\text { Scales } \\
\text { for assessing } \\
\text { factors } \\
\text { and trends }\end{array}$ \\
\hline $\begin{array}{l}\text { Project } 1 . \\
\text { (DP) }\end{array}$ & $\begin{array}{c}\text { "Resource- } \\
\text { oriented" } \\
\text { (R. Grant, 1987) }\end{array}$ & Digraph & $\begin{array}{l}\text { Building methods: } \\
\text { SWOT analysis. PESTLE analysis. } \\
\text { Implicit repertoire lattices of S. Hinckle. } \\
\text { Interaction matrix (L. Jones, 1982) } \\
\text { Analysis methods: } \\
\text { Models of linear dynamics F. Roberts. } \\
\text { Scenario analysis method. }\end{array}$ & $\begin{array}{l}\text { 5-point bipolar } \\
\text { linguistic }\end{array}$ \\
\hline $\begin{array}{c}\text { Project } 2 . \\
(\mathrm{RP})\end{array}$ & $\begin{array}{l}\text { "School } \\
\text { of competencies" } \\
\text { (C. Prahalad, } \\
\text { G. Hamel, 1990) }\end{array}$ & $\begin{array}{c}\text { Relational } \\
\text { Matrices } \\
\text { (ASQ Matrix } \\
\text { XL Diagram) } \\
\quad[8]\end{array}$ & $\begin{array}{c}\text { Building methods: } \\
\text { Ishikawa diagrams. } \\
\text { VRIO analysis (J. Barney, 1987). } \\
\text { eTOM.4.0 business process model } \\
\text { (Intern. Telecommunication Union/Stand- } \\
\text { ardization Sector). "Consumer opinion } \\
\text { model" (IBM, USA). "Resource model" } \\
\text { (American Society for Quality, USA). } \\
\text { Analysis methods: } \\
\text { Fuzzy causal grid analysis [8]. } \\
\text { T. Saati hierarchy analysis method. }\end{array}$ & $\begin{array}{l}\text { 10-point } \\
\text { linguistic }\end{array}$ \\
\hline $\begin{array}{c}\text { Project } 3 . \\
\text { (RP) }\end{array}$ & $\begin{array}{l}\text { "Migration } \\
\text { strategy" [1] }\end{array}$ & Digraph & $\begin{array}{l}\text { Building methods: } \\
\text { SWOT analysis. PESTLE analysis. } \\
\text { "Competitive analysis model" } \\
\text { (M. Porter, 2003). } \\
\text { Methods of psychosemantics and } \\
\text { multidimensional non-metric scaling } \\
\text { (M. Davidson, 2003). } \\
\text { Analysis methods: } \\
\text { Qualitative dynamics models based on } \\
\text { rules [5] and temporal logic } \\
\text { (Pospelov, 1986). }\end{array}$ & $\begin{array}{l}\text { 5-point bipolar } \\
\text { linguistic }\end{array}$ \\
\hline $\begin{array}{c}\text { Project } 4 \\
\text { (RP) }\end{array}$ & $\begin{array}{l}\text { Economist } \\
\text { Intelligence } \\
\text { Unit concept } \\
\text { (EIU, 2004) }\end{array}$ & $\begin{array}{l}\text { Minsky } \\
\text { frames }\end{array}$ & $\begin{array}{c}\text { Building methods: } \\
\text { System analysis + Business review } \\
\text { PESTLE analysis } \\
\text { Analysis methods: } \\
\text { Scenario modeling method }\end{array}$ & $\begin{array}{l}\text { 10-point } \\
\text { linguistic }\end{array}$ \\
\hline
\end{tabular}

Legend: DP - demonstration prototype; RP - research prototype; BM - CM building methods; AM - CM analysis methods. 
3. One of the key issues of cognitive management is that of choosing a reasonable level of detail ("granulation") of cognitive maps. It stems from the fact that the use of cognitive maps with a low detail level often leads to the loss of details wherein the devil is known to be. A critical review of relevant literature and discussions with colleagues has led us to conclude that the issue requires further study and can be regarded as one of the areas for further improvement of cognitive analysis, in particular, the development of an effective "multiscaling" mechanism similar to the design proposed by the RAND Corporation [31].

4. Serious difficulties arise in the scenario analysis of the strategies developed. Nonmonotonic dynamics of the external environment and the need for a multivariate analysis of strategies in a broad "scenario corridor" require the development of an engineering modeling technique that is different from that offered by higher mathematics [19, 22].

5. Collaboration with employees of enterprises has shown that they did not have a clear opinion on the effectiveness of cognitive modeling. At the same time, 12 out of 17 respondents showed active interest and felt that cognitive modeling is a promising and useful technology. At the same time, our observations have revealed a very important latent feature of cognitive analysis: it stimulates the cognitive and creative activity of strategy developers in the most complex and critical phase of "strategic thinking" - the phase of afferent synthesis of strategic decisions.

6. The work in the projects has convincingly confirmed the fact that the suitability of cognitive models depends primarily on the "quality" of knowledge in its foundation, the carriers of which are the strategy developers, their competencies and professional experience. Cognitive modeling only enhances and expands their analytical potential.
7. The high changeability of the business environment today imposes stringent requirements on the timeframe of constructing and testing cognitive models. This is the fundamental difference between cognitive management and many other cognitive applications. In this regard, it becomes critically important to create effective support tools (high-level languages, system shells, scenario networks) for the "quick" development and testing of cognitive models - an issue that is currently completely dismissed by theorists of the cognitive school.

\section{Conclusion}

Note some general considerations regarding the advantages and shortcomings of cognitive modeling, which, according to the analysis of the few applied studies, are relevant for other applications of the cognitive approach.

1. As in all "knowledge-based" technologies, the necessary condition for success is, first, the experts involved (top managers, business consultants) possessing high-quality knowledge and, second, the involvement of a knowledge engineer playing a key role in the initial stages of the cognitive process.

2. The fundamental advantages of the cognitive approach are:

- the capability to study the dynamics of a business situation in a complex, rapidly changing PEST environment, when the available data is not enough to build a complete simulation model;

- the capability to study business situations, taking into account the multi-factorial "institutional shell" of the enterprise [17];

- the capability to study business situations in the presence of multiplicative and feedback connections between environmental factors, as well as in the presence of various threshold effects. 
None of the many traditional strategic management support tools have such capabilities.

3. Cognitive analysis opens up new perspectives for decision theory. The possibility of purposeful generation of optimal strategies, which is not available in well-known commercial DSS packages, determines a fundamentally new approach to decision-making: not "choosing the best solution from the many available alternatives" (RAND Corporation paradigm), but purposefully generating the "best solution".

4. Testing of cognitive models has revealed a number of challenges:

- due to the discrete structure of models, only a rough approximation of continuous processes is possible. One has to carefully consider the sequence of factors in causal networks and take into account whether the effects of some factors on others are in sync, or whether they are offset from each other;

- one has to be careful when parameterizing cognitive maps, especially when evaluating the strength of causal relations that can change during scenario transformations;

- parameterization of cognitive models in the case of complex (multi-factorial) cognitive maps faces an "integrity issue." The widespread belief that the values of each factor and each causal relation can be determined individually is, in our opinion, deeply erroneous. According to our observations, although these assessments are made individually, they are highly correlated with the gestalt of the problem situation formed by strategy developers on an intuitive level [32]. This fact severely limits the working formats of cognitive maps and makes it unproductive to deal with popular large-format maps, in which basic factors and causal relations number in tens or even hundreds.

5. The complex economic environment in which enterprises operate today significantly limits the possibilities of traditional economic and mathematical modeling. In the problems of strategic choice, knowledge-based modeling becomes relevant. Modern strategic research virtually turns into a complex engineering art [18], shaping a new promising trend of managerial business analytics. Critical analysis shows that cognitive management is currently the only uncontested paradigm that can ensure the successful implementation of this trend [33]. However, it also shows that the field of cognitive management engineering today is riddled with issues that must be solved lest the cognitive school of management, like thirty years ago, remain a tempting and promising potential rather than a practical tool.

\section{References}

1. Newman W. (1951) Management action: Organization and management technique. Columbian University (in Russian).

2. Thompson Jr. A.A., Striklend III A.G. (2009) Strategic management: concepts and situations for the analysis. $12 \mathrm{ed}$. Moscow: Williams (in Russian).

3. Drucker R. (2012) Management challenges for the 21st century. London, New York: Routledge. Taylor \& Francis Group.

4. Narayanan V.K., Zane L.K., Kemmerer B. (2011) The cognitive perspective in strategy:

An integrative review. Journal of Management, vol. 37, no 1, pp. 305-323.

DOI: 10.1177/0149206310383986. 
5. Hodginson G. (2011) Cognitive process in strategic management: Some emerging trends and future direction. Handbook of industrial, work \& organizational psychology. London: SAGE Publication, vol. 2, pp. 401-441.

6. Ross D. (2005) Economic theory and cognitive science: Microexplanation. MIT Press.

7. Mintzberg H., Lampel J., Ahlstrand B. (2005) Strategy safari: A guide tour through the wilds of strategic management. New York: Free Press.

8. Lee J.D., Kirlik A., Dainoff M.J., eds. (2013) The Oxford handbook of cognitive engineering. Oxford library of psychology. New York: OUP USA.

9. Waterman D.A. (1986) Guide on expert systems. Addison-Wesley.

10. Hodgkinson G.P., Healey M.P. (2007) Cognition in organizations. Annual Review of sychology, no 59, pp. 387-417. DOI: 10.1146/annurev.psych.59.103006.093612.

11. Johnson-Laird P.N. (1980) Mental models in cognitive science. Cognitive Science, no 4, pp. 71-115. DOI: 10.1207/s15516709cog0401_4.

12. Roberts F. (1976) Discrete mathematical models with application to social, biological and environmental problems. Englewood Cliffs, New Jersey: Rutgers University, Prentice-Hall.

13. Schwenk C.R. (1988) The cognitive perspective on strategic decision making. Journal of Management Studies, vol. 25, no 1, pp. 41-55. DOI: 10.1111/j.1467-6486.1988.tb00021.x.

14. Haleblian J., Rajagopalan N. (2006) A cognitive model of CEO dismissal: Understanding the influence of board perceptions, attributions and efficacy beliefs. Journal of Management Studies, no 43, pp. 1009-1026. 10.1111/j.1467-6486.2006.00627.x.

15. Porac J.F., Thomas H. (2002) Managing cognition and strategy: Issues, trends and future directions. Handbook of strategy and management (Eds. A. Pettigrew, H. Thomas, R. Whittington). London: SAGE Publisher, pp. 165-181.

16. Eden C., Ackermann F. (2001) SODA - The principles. Rational analysis for a problematic world revisited: problem structuring methods for complexity, uncertainty and conflict (Eds. J. Rosenhead, J. Mingers). Chichester: Wiley, pp. 21-41.

17. Balatsky E. (2006) The dialectic of cognition and the new paradigm of economic science. World Economy and International Relations, no 7 (in Russian).

18. Pospelov D.A. (2001) Theory and practice of situational management. Moscow: Nauka (in Russian).

19. IEEE Proceedings of the International Conference on Cognitive and Computational Aspects of Situation Management (CogSIMA) (2011-2019) series. Available at: https://edas.info/web/ cogsima2019/home.html (accessed 20 February 2020).

20. Best value business \& consulting toolkits. Created by management consultants previously from: Deloitte, McKinsey\&Company, BCG Strategy Consultants. Available at: https://www.slidebooks.com/products/strategy-toolkit?gclid=EAIaIQobChMIhfSMj8qz4gIVgobVCh1xTwW2E AMYASAAEgJ8XfD_BwE\&variant=17648810693 (accessed 20 February 2020).

21. Gallopin G.C. (1977) Modeling incompletely specified complex systems. Third International Symposium on Trends in Mathematical Modelling, S.C. Bariloche, December 1976, UNESCO-Fundacion Bariloche.

22. IEEE Proceedings of the International Conference on Cognitive Modeling (ICCM) series (1996-2019). Available at: https://iccm-conference.github.io/previous.html (accessed 20 February 2020). 
23. Avdeeva Z.K., Kovriga S.V. (2011) Formation of a strategy for the development of socio-economic objects based on cognitive maps. Saarbrucken: LAP LAMBERT Academic Publishing.

24. Cummins S., Wilson D., Angwin D, Bilton C., Brocklesby J., Doyle P., Galliers B., Legge K., McGee J., Newell S., Pettigrew A., Smith C., Wensley R. (2003) Images of strategy. Oxford: Blackwell Publishing.

25. Rodin D.V. (2008) Conceptual approaches to the formation and implementation of organizational strategies. System Management, issue 1(2). Available at: http://sisupr.mrsu.ru/ wp-content/uploads/2014/11/21-rodin.pdf (accessed 20 February 2020) (in Russian).

26. Aithenhead A.M., Slack J.M., Eds. (1994) Issues in cognitive modeling. Lea: Hove.

27. Buchanan B., Bechtal R., Bennett J., Clancey W., Kulikowski C., Mitchell T., Waterman D.A. (1983) Constructing an expert system. Building expert system (F. Hayes-Rath, D. Waterman, D. Lenet, eds.). Addison-Wesley, 1983.

28. Solow R. (1987) We'd better watch out. Book review. New York Times, 12 July 1987.

29. Karayev R.A. (2013) Choice of a strategy of regional ICT-management. Cognitive paradigm. International Journal of Managing Information Technology, vol. 5, no 3, pp. 17-30. DOI: 10.5121/ijmit.2013.5303.

30. Karayev R.A. (2015) Cognitive approach and its application to the modeling of strategic management of enterprises. Knowledge engineering: Principles, methods and applications (Ed. A. Perez Gama). New York: Nova Science, pp. 79-101.

31. Davis P.K., Kahan J.P. (2007) Theory and methods for supporting high-level decision making. Santa Monica, CA: RAND Corporation, TR-422-AF.

32. Bays P.M., Husain M. (2008) Dynamic shifts of limited working memory resources in human vision. Science, vol. 321, no 5890, pp. 851-854. DOI: 10.1126/science.1158023.

33. Polterovich V.M. (1999) Institutional traps and economic reforms. Economics and Mathematical Methods, vol. 35, no 2, pp. 3-20 (in Russian).

\section{About the authors}

\section{Robert A. Karayev}

Dr. Sci. (Tech.);

Professor, Head of Ecosystems Modeling Laboratory,

Institute of Control Systems, Azerbaijan National Academy of Sciences,

9, B. Vahabzade Street, Baku AZ1141, Azerbaijan;

E-mail: karayevr@rambler.ru

\section{Natella Yu. Sadikhova}

Researcher, Institute of Control Systems, Azerbaijan National Academy of Sciences,

9, B. Vahabzade Street, Baku AZ 1141, Azerbaijan

E-mail: natella5@rambler.ru 